\title{
A Summary of Health Hazard Evaluations: Issues Related to Occupational Exposure to Fire Fighters, 1990 to 2001
}

\section{DEPARTMENT OF HEALTH AND HUMAY SERVICES}

Centers for Disease Control and Prevention

National Institute for Occupational Safety and Health 


\title{
ORDERING INFORMATION
}

Individual Health Hazard Evaluations (HHEs) presented in this document may be requested by referencing the HETA number listed. To receive these documents or other information about occupational safety and health topics, contact the National Institute for Occupational Safety and Health (NIOSH) at

\author{
NIOSH-Publications Dissemination \\ 4676 Columbia Parkway \\ Cincinnati, OH 45226-1998
}

Telephone: 1-800-35-NIOSH (1-800-356-4674)

Fax: 1-513-533-8573

E-mail: pubstaft@cdc.gov

or visit the NIOSH Web site at www.cdc.gov/niosh

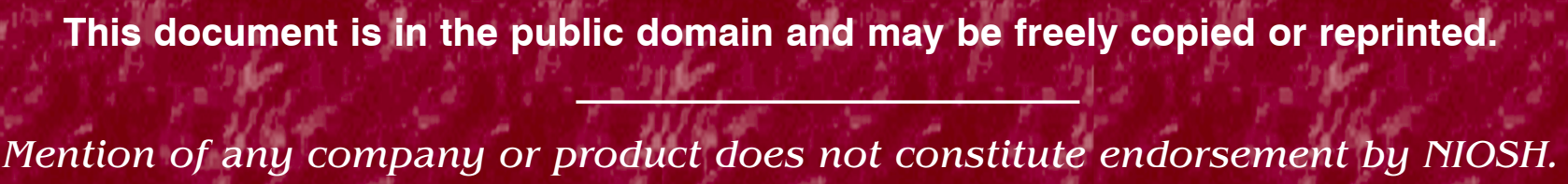

DHHS (NIOSH) Publication No. 2004- 115 
The Hazard Evaluations and Technical Assistance (HETA) Program responds to requests from employers, employees, employee representatives, other Federal agencies, and State and local agencies. Through a staff of industrial hygienists (IHs), engineers, occupational physicians, epidemiologists, other health professionals, and support personnel, the Hazard Evaluations and Technical Assistance Branch (HETAB) collaborates with appropriate personnel in other divisions of the National Institute for Occupational Safety and Health (NIOSH) to respond to approximately 450 requests for assistance each year. The typical HETA response to a request for assistance results in (l) an evaluation of whether chemical, physical, biological, or other agents are hazardous as used or found in the workplace and (2) the development of recommendations for control procedures, improved work practices, and medical programs to reduce exposure levels and prevent adverse health effects. Health Hazard Evaluation (HHE) site visits are conducted if warranted, and interim and final reports are developed and distributed to employees, unions, management, and relevant State and Federal agencies. When the HETA request is from a Federal, State, or local agency for assistance in investigating another workplace, NIOSH provides only the technical assistance (TA) requested and does not conduct a complete HHE. The results of individual evaluations may trigger wider studies of similar exposures in other settings or may stimulate recommendations for implementation or modification of health standards. Approximately 12,000 evaluations have been completed since the inception of the HETA Program in 1972.

Requests received by the HETA program often reflect widespread occupational problems, such as the hazards of fire fighting. One-hundred and fifty-nine fire fighter-related HHEs were requested from 1990 to 2001; the majority of the requests came from city and county fire departments, the International Association of Fire Fighters (IAFF), and the U.S. National Park Service (NPS). This document contains a summary of 30 HHEs related to fire fighting that involved a site visit between 1990 and 2001, categorized by the focus. Of the 30 HHEs, 7 were related to respiratory health effects and safety and health programs and procedures, 8 to diesel exhaust, 5 to forest fire fighting, 6 to chemical fires, 2 to communicable diseases, 1 to arsenic poisoning, and 1 to inspecting fire scenes at buildings with chromated copper arsenic (CCA)-treated lumber. Unlike HHEs in the previous decade (1980-1989), not many fire-fighting HHEs were related to chemical fires (6 compared with 30), and none were related to noise exposure (0 compared with 9 ). In most cases, multiple exposures were investigated at the work site; generic as well as site-specific recommendations were always provided.

The purpose of this document is to amass the past decade of fire fighting HHEs in a concise format for easy reference and examination by NIOSH researchers, customers, and partners. Any individual reports or letters of interest can easily be requested. The scope and presentation of the individual HHEs vary based on the requesters' needs and the project officers' professional judgment. The editors of this document are not at liberty to change the overall findings of each HHE report. The document is not meant to be a state-of-the-art review, but instead, it is intended to provide general insight into the types of fire fighter HHE requests received, and HETAB's response to them.

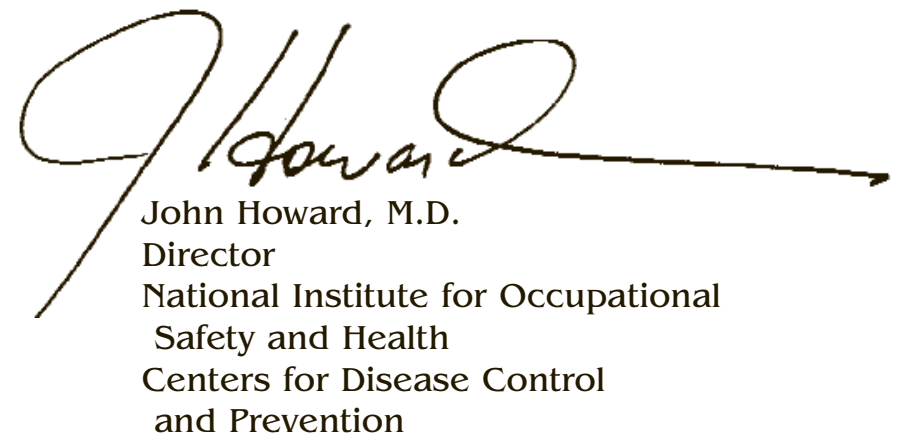




\section{cONTRIBUTORS}

Prepared by

Beth Donovan Reh, M.H.S.

\section{Editor}

Jane Weber, M.Ed.

Desktop Publishing and Design

Donna Pfirman

NIOSH Printing Office

Penelope Arthur

Web Production

David Wall

Donna Pfirman

Contributing Project Officers on Health Hazard Evaluations

Steve Berardinelli

Leo M. Blade, C.I.H.

Mary Brown, D.V.M.

Yvonne Boudreau, M.D.

G.E. Burroughs, C.I.H.

Calvin K. Cook, B.S.

John Decker, M.S., C.I.H.

Scott Deitchman, M.D., M.P.H.

Alan Echt, M.P.H., C.I.H.

Anne T. Fidler, Sc.D.

Thomas K. Hodous, M.D.

Brad Husberg, R.N., M.S.P.H.

John E. Kelly, M.S.

Max Kiefer, C.I.H.

Gregory M. Kinnes, M.S., C.I.H.

Steven W. Lenhart, C.I.H.

Deanna Letts, R.N., M.S.

Charles S. McCammon, Ph.D., C.I.H.

Tim R. Merinar, M.S.

Gary P. Noonan, M.P.A.

Ted A. Pettit, M.S.

Christopher M. Reh, M.S.

Kevin Roegner, M.P.H.

John Sheehy, Ph.D., C.I.H.

Ruth A. Shults, R.N., M.P.H.

Dwayne Smith, C.S.P.

David C. Sylvain, M.S., C.I.H.

Samuel Terry, B.S.

Doug Trout, M.D.

Nina Turner, Ph.D.

\section{ABBREVIATIONS}

ACGIH ${ }^{\circledR} \quad$ American Conference of Governmental Industrial Hygienists

ATF Alcohol, Tobacco, and Firearms

ATSDR Agency for Toxic Substances and Disease Registry

BLM Bureau of Land Management

CAER Community Awareness and Emergency Response

CCA Chromated copper arsenic

CDHS California Department of Health Services

CDPHE Colorado Department of Public Health and Environment

CFK Coburn, Foster, Kane

CI Confidence interval

CL Ceiling limit

CNS Central nervous system

CO Carbon monoxide

$\mathrm{CO}_{2} \quad$ Carbon dioxide

$\mathrm{COHb}$ Carboxyhemoglobin

Cr VI Chromium VI

CVD Cardiovascular disease

DOA U.S. Department of Agriculture

DOI U.S. Department of the Interior

DSR Division of Safety Research

EC Elemental carbon

EKG Electrocardiogram

EMS Emergency medical services

EPA U.S. Environmental Protection Agency

$\mathrm{FEF}_{25-75}$ Mean forced expiratory flow during the middle half of the FVC

$\mathrm{FEV}_{1} \quad$ Forced expiratory volume in 1 second

$\mathrm{FEV}_{1} / \mathrm{FVC}$ Ratio of $\mathrm{FEV}_{1}$ to FVC

FFFI\&PP Fire Fighters Fatality Inv. and Prevention Program

FS Forest service (DOA)

FVC Forced vital capacity

FY Fiscal year

GA General area (air sample)

HBV Hepatitis B virus

HCV Hepatitis C virus

HETA Hazard Evaluations and Technical Assistance 
HETAB Hazard Evaluations and Technical Assistance Branch

HHE Health hazard evaluation

HIV Human immunodeficiency virus

IAFF International Association of Fire Fighters

ICS Incident command system

IH Industrial hygiene or industrial hygienist

LOD Limit of detection (analytical method)

LOQ Limit of quantitation (analytical method)

MDC Minimum detectable concentration (the smallest amount of a material that can be reliably detected). The MDC is calculated by dividing the analytical limit of detection by a representative air volume.

mg Milligrams

$\mathrm{mg} / \mathrm{m}^{3} \quad$ Milligrams per cubic meter of air

MQC Minimum quantifiable concentration (the smallest amount of a material that can be reliably measured). The MQC is calculated by dividing the analytical LOQ by a representative air volume.

MSDS Material safety data sheet

MSHA Mine Safety and Health

Administration

MTBE Methyl t-butyl ether

ND Not detected

NFPA National Fire Protection

Association

NIOSH National Institute for

Occupational Safety and Health

NPS National Park Service (DOI)

NO Nitrogen oxide

$\mathrm{NO}_{2} \quad$ Nitrogen dioxide

$\mathrm{NO}_{\mathrm{x}} \quad$ Nitrogen oxides
NWCG National Wildfire Coordinating Group

OC Organic carbon

OSHA Occupational Safety and Health Administration

PAHs Polycyclic aromatic hydrocarbons

PASS Personal alert safety system

device

PCB Polychlorinated biphenyls

PBZ Personal breathing-zone (air sample)

PEL Permissible exposure limit (OSHA)

PFT Pulmonary function tests

PPE Personal protective equipment

ppm Parts (of a contaminant) per million parts

REL Recommended exposure limit (NIOSH exposure criteria)

RPM Respirable particulate matter

RPNOR Respirable particulates not otherwise regulated

SCBA Self-contained breathing apparatus

SIC Standard industrial classification

$\mathrm{SnCl}_{4} \quad$ Stannic chloride

$\mathrm{SO}_{2} \quad$ Sulfur dioxide

$\mathrm{SO}_{\mathrm{x}} \quad$ Sulfur oxides

SOP Standard operating procedure

TA Technical assistance

TB Tuberculosis

TLV ${ }^{\circledR} \quad$ Threshold limit value (ACGIH ${ }^{\circledR}$ exposure criteria)

TST Tuberculin skin test

TWA Time-weighted average

USFS United States Forest Service

VOCs Volatile organic compounds

$\mu \mathrm{g} / \mathrm{m}^{3} \quad$ Micrograms of contaminant per cubic meter of air (a unit of concentration)

Hm Micrometer 


\section{BACKGROUND}

Fire fighting continues to be one of the more hazardous industries in this country. The occupational environment for fire fighters is somewhat unique: exposures are varied, often high, and intermittent. They occur in circumstances of extreme physical and mental stress where the only means of exposure control is selfcontained breathing apparatus (SCBAs). Exposures can include smoke and particulate matter, carbon monoxide $(\mathrm{CO})$, nitrogen dioxide $\left(\mathrm{NO}_{2}\right)$, hydrogen chloride, hydrogen cyanide, sulfur dioxide $\left(\mathrm{SO}_{2}\right) /$ sulfuric acid, acrolein, formaldehyde and acetaldehyde, benzene and many other organic chemicals, and any chemicals that might be located at the fire scene. Many of these exposures cause acute effects, but others may cause chronic effects, such as respiratory health effects and decreased lung function from repeated smoke exposures or cancer from repeated exposures to diesel exhaust, benzene, polycyclic aromatic hydrocarbons (PAHs), asbestos, or formaldehyde. A high potential exists for burns, acute trauma, and musculoskeletal injuries. Communicable diseases are becoming a major concern, especially blood-borne pathogens and tuberculosis (TB). Other health effects associated with fire fighters are cardiovascular disease, reproductive hazards, hearing loss, and occupational stress. A detailed summary of these exposures and health effects can be found in Occupational Medicine: State of the Art Reviews: Fire Fighters' Safety and Health. ${ }^{2}$

The 30 Health Hazard Evaluations (HHEs) summarized in this document are grouped into the following six categories:

1. Respiratory health effects and safety and health programs and procedures (7)

2. Diesel exhaust exposures (8)

3. Forest fire-fighting (5)

4. Chemical diseases (6)

5. Communicable diseases (2)

6. Other (2)

Along with conducting fire-fighting HHEs, the Hazard Evaluations and Technical
Assistance Branch (HETAB) began a project under the Fire Fighter Fatality Investigation and Prevention Program (FFFI\&PP) during fiscal year (FY) 1998 to investigate line-of-duty cardiovascular fatalities suffered by fire fighters. Approximately 45 fire fighters suffer fatal heart attacks each year, and NIOSH is investigating these fatalities to generate hypotheses for prevention and intervention activities. Each investigation includes an assessment of the physiologic and psychologic demands of the job, workplace organization factors, and individual risk factors. Each investigation results in a succinct report for the affected fire department as well as the country's fire service and is included as part of the larger annual report. From 1998 to 2001, 62 investigative reports have been completed, with an additional 13 pending completion. These reports have been distributed to more than 30,000 fire departments representing more than 1 million fire fighters. They are also available on the NIOSH fire fighter Web site www.cdc.gov/niosh/firehome.html. One peer-reviewed journal article has been published, and seven presentations have been given at national meetings ${ }^{3}$. Finally, as an expert of cardiovascular disease (CVD) among those employed in the fire service, one program member was invited to become a member of the National Fire Protection Association (NFPA) Standard 1582, Medical Requirements of Fire Fighters and Information for Fire Department Physicians.

\section{SAFEX AND HEALTH PROGRAMSAND PROCEDURES}

Seven HHEs are summarized below that involved review of and recommendations for fire department safety and health programs and procedures. Four of the HHEs were requested because of a fatality or severe respiratory health effects, two others were requested specifically for review of department safety and health procedures, and one was requested because of concerns about psychologic changes and cardiac abnormalities possibly related to job stress. All seven of these HHEs involved some or all of the recommendations that 
have been published in the $1994 \mathrm{NIOSH}$ Alert Preventing Injuries and Deaths of Fire Fighters. ${ }^{4}$ The Alert presents the current OSHA and MSHA Regulations, consensus standards, a case report, and recommendations for any fire department. The recommendations from the Alert are presented in the appendix of this document.

\section{HETA 90-0205 November 1990}

\section{Requester: Union}

Purpose: To investigate conditions of a residential fire during which two fire fighters died

Keywords: SIC 9224 (fire departments), fire-fighting, deaths, cyanide, smoke, $\mathrm{CO}$, COHb, SCBA

Abstract: In January 1990, three professional fire fighters combating a residential fire became unconscious and were brought out of the structure in full cardiac arrest-one was successfully resuscitated; two died. The IAFF contacted NIOSH in April, and a team (consisting of a physician, a respirator specialist, and an occupational safety and health specialist) conducted an investigation of the incident. No environmental samples were collected at the time of the fire, but arterial blood gas samples from the two deceased fire fighters that were taken after their arrival at the hospital showed COHb levels of $17 \%$ and $38 \%$. Postmortem blood cyanide tests were negative. A hazardous materials team from the county fire department had investigated the structure 3 hours after the fire and did not find any hazardous materials. The fire fighters were all wearing SCBAs, and an air sample of the supplied breathing air was taken the morning after the incident and determined to be of higher quality than was required. The medical examiner's office said the cause of death for both fire fighters was smoke inhalation based on the abundance of soot in the lower trachea, large mainstream bronchi, and smaller bronchiolar radicles. Given the evidence, NIOSH investigators could not make a definitive determination of the actual cause of death but said that $\mathrm{CO}$ was more likely the cause than cyanide or an unknown toxin resulting from combustion. They also suggested that the exposure occurred in the structure and that for some unknown reason the fire fighters' SCBA units were probably not delivering air to the exclusion of outside air at some point. They recommended that in similar situations grab samples of the atmosphere should be collected immediately using a gas-tight bag, blood samples should be collected as soon as possible, times should be documented accurately for any sample collection or significant event, and investigations such as this one should be conducted as soon as possible after the incident and should involve an IH to take samples of suspect material.

\section{HETA 90-0395-2121 June 1991}

Requester: Union

Purpose: To assess the safety and health practices of a county fire department after the death of an employee

Keywords: SIC 9224 (fire departments), fire-fighting, fire fighters, heat stress, heat stroke, mortality

Abstract: The IAFF asked NIOSH to assess the safety and health practices of a county fire department after a 25-year-old fire fighter died of heat stroke while fighting a brush fire. NIOSH investigators toured the fire scene, conducted personal interviews with 25 fire fighters and support personnel, and reviewed incident reports, incident command procedures, and other documents. The deceased fire fighter and his captain had advanced separate booster lines and fought the brush fire for approximately 1 hour. The fire fighter then rested alone at the engine while the captain reported to command. Upon arriving at the command station, the captain reported that the fire fighter was in need of rehabilitation, then entered rehabilitation himself. Over the next few hours several individuals mistakenly identified other fire fighters as the downed fire fighter and assured the captain that he had rested and was then reassigned. The fire fighter's body was discovered during cleanup operations. On the basis of the 
information obtained during this investigation, the NIOSH investigators concluded that a preventable series of events preceded the fire fighter's death. Recommendations were made for incident command and safety procedures, as well as medical monitoring, rehabilitation of fire fighters at fire scenes, and rehydration schedules.

\section{HETA 93-0040-2315 May 1993}

Requester: Management

Purpose: To evaluate the exposures during qualitative respirator fit testing using irritant smoke

Keywords: SIC 9224 (fire departments), fire-fighting, hydrogen chloride, irritant smoke, respirator fit testing

Abstract: NIOSH conducted an HHE in response to a request from the fire chief of a city fire department. The HHE request was received after four fire fighters reported experiencing either skin irritation or eye irritation as a result of qualitative respirator fit tests using irritant smoke. Each of the 186 fire fighters from the department were fit tested in 1992 while wearing a SCBA (with nose cup) operated in the pressure-demand mode. The fit-testing method involved puffing irritant smoke from air flow indicator tubes into a test hood that encompassed the fire fighter's head and the SCBA's facepiece. The tubes contained $\mathrm{SnCl}_{4}$, which reacts with ambient humidity to liberate a white fume containing hydrochloric acid and tin compounds. The health risks associated with the use of irritant smoke were evaluated by (1) conducting particle size analysis of the "smoke" emitted from air flow indicator tubes and (2) measuring the concentration of hydrogen chloride produced by these tubes. Count median diameters of the smoke ranged from $0.33 \mu \mathrm{m}$ to $0.63 \mu \mathrm{m}$ with geometric standard deviations ranging from 1.35 to 2.13 .

Concentrations of hydrogen chloride measured without the hood in place on a day with low relative humidity (14\%) ranged from $<1$ to $2,700 \mathrm{ppm}$. The highest concentration measured inside the test hood was also 2,700 ppm. Concentrations of hydrogen chloride measured without the hood in place on a day with high relative humidity (53\%) ranged from 100 to $11,900 \mathrm{ppm}$. The highest concentration measured inside the test hood was $14,400 \mathrm{ppm}$. Because fire-fighting activities frequently occur in highly toxic atmospheres or those immediately dangerous to life or health, the use of a quantitative fit test was recommended. It was also recommended that they use the full facepiece air-purifying versions of the respirators. The sampling results of this study suggested that high concentrations of hydrogen chloride were emitted from irritant smoke tubes and that exposure to the fume produced by these tubes should be considered a health risk.

\section{HETA 94-0244-243 1 June 1994}

Requester: Union

Purpose: To determine if the SCBA failed or contributed to the death of two fire fighters, assess the accountability of personnel utilizing SCBA in the hazard area, and evaluate the training of command and suppression personnel

Keywords: SIC 9224 (fire departments), fire-fighting, fire fighters, death, self-contained breathing apparatus, SCBA

Abstract: NIOSH DSR received a request from the IAFF who was investigating the circumstances of the deaths of two fire fighters. The IAFF requested technical assistance in determining if the SCBA failed or contributed to the fire fighters' deaths, assessing the accountability of personnel utilizing SCBA in the hazard area, and evaluating the training of command and suppression personnel. The investigation was coordinated through the city fire department and consisted of four phases: (1) the interview of several fire fighters, fire chiefs, union representatives, safety personnel, fire investigators, and the director of fire services, (2) the site visit to the eleven-story high-rise apartment building involved in the fire, (3) the review of respirator maintenance records of the fire department, and (4) the evaluation of 
breathing apparatus ( 4 units) worn by the first responders to the fire. NIOSH investigators identified several contributing factors to this incident: (1) failure to follow established departmental policies and procedures at the fire scene, (2) an inadequate respirator maintenance program, (3) lack of fire fighter accountability at the fire scene, and (4) lack of the use of PASS devices at the fire scene.

\section{HETA 94-0390-2822 September 2000}

\section{Requester: Union}

Purpose: To investigate concerns about psychologic changes and cardiac abnormalities possibly related to job stress from long work hours, night work, sleep deprivation, and other job stressors in a city fire department

Keywords: SIC 9224 (fire protection), job stress, cardiovascular disease, arrhythmia, anxiety, depressive symptoms, depression

Abstract: NIOSH received a request from the IAFF to investigate concerns about psychologic changes and cardiac abnormalities possibly related to job stress from long work hours, night work, sleep deprivation, and other job stressors in a city fire department. NIOSH investigators met with department and IAFF representatives to discuss the HHE request, visited three fire stations, observed work practices and organization, obtained EKG results from annual physical examinations, and conducted a health survey. Full-time department employees filled out a questionnaire about personal characteristics, job history, medical history, cardiovascular symptoms, mental health (including depressive symptoms and anxiety), and job stress. For all study participants, NIOSH investigators obtained EKG results from the most recent annual physical examinations. A NIOSH occupational physician read the EKGs using standard clinical criteria. Investigators did statistical modeling to learn whether job stressors were related to depressive symptoms, anxiety, and sinus arrhythmia.

Eighty-one percent $(210 / 260)$ of the fulltime employees participated in the questionnaire survey, and 196 participants from 10 fire stations were eligible to participate in the study. All but three participants were male, and the majority $(75 \%)$ were 30 to 40 years old. Most participants were in one of the following four job titles: fire fighter (66 persons, 34\%), fire fighter/paramedic (31 persons, 16\%), fire engineer (31 persons, 16\%), and fire captain (30 persons, 15\%). Because of the small number of participants with any single condition other than sinus arrhythmia, investigators focused further analysis on this finding. No meaningful linear relationship between sinus arrhythmia and any of the job stressors studied was found. Thus, the evaluation found neither severe psychological problems nor a consistent pattern of clinically significant cardiac arrhythmias. It did, however, find evidence that certain aspects of the job affected the psychologic well-being of employees-uncertainty, disharmony, work effort, and involvement in specific critical incidents, including fires with multiple burn victims and self-reported hazardous materials exposure. Recommendations were offered to ensure that personnel were receiving appropriate medical surveillance and to address concerns about job stress.

\section{HETA 95-0086 March 1995}

Requester: Management

Purpose: To investigate a fire scene where at least 40 fire personnel had experienced respiratory problems and injuries, to develop recommendations to prevent similar episodes in the future, and to provide consultation with The Johns Hopkins University School of Hygiene and Public Health who was evaluating the affected fire fighters

Keywords: SIC 9224 (fire departments), carbon monoxide, $\mathrm{CO}$, carbon dioxide, $\mathrm{CO}_{2}$, irritant gases, oxygen deficiency, pulmonary function tests, PFTs

Abstract: NIOSH was contacted, along with ATSDR, the State Department of the Environment, and The Johns Hopkins University School of Hygiene and Public Health, to investigate a fire scene where at least 40 fire personnel had experienced 
respiratory problems and injuries and to develop recommendations to prevent similar episodes in the future. Investigators determined that since the fire was not suppressed for 6 hours, a significant smoke exposure was likely. Also, at least some of the SCBA air was contaminated with vehicle exhaust and gasoline fumes. Several recommendations were made, including following the guidelines in the NIOSH Alert: Preventing Injuries and Deaths of Fire Fighters and developing a respiratory protection program in accordance with the OSHA respiratory protection standard and National Fire Protection Association 1404 Standard for a Fire Department SCBA Program.

\section{HETA 97-0166-2726 February 1999}

Requester: Union

Purpose: To assess the incident response procedures used during a fire in a high-rise office building

Keywords: SIC 9224 (fire departments), fire-fighting, fire fighters, incident command system, ICS, self-contained breathing apparatus, SCBA, high-rise building

Abstract: NIOSH received a request for an HHE from the IAFF on behalf of fire fighters from a city fire department to assess the incident response procedures used during a fire in a high-rise office building. The IAFF reported that more than 200 fire fighters and other response personnel were involved in the incident. NIOSH investigators conducted a site visit to the fire department and held an opening conference with representatives of the department and local union. Also, individual private interviews were held with several fire fighters and other members of the department who responded to the incident. Several standard operating procedures (SOPs) and other pertinent records were obtained for review. Individual post-incident reports from the line commanders and several other fire fighters were also requested and subsequently reviewed. The fire department encountered several difficulties while responding to this fire. Fire suppression activities were hampered because the building was a high-rise and because of problems locating the fire because of the complex building layout. During the incident, there was confusion regarding actual command responsibility because the SOPs were apparently not followed. In addition, the department did not have a formal ICS in place to assist with managing an incident that required the response of all their resources and mutual aid from other fire departments. The SOP system, according to the information that was reviewed, did not adequately address the several considerations specific to a highrise situation. These situations include expanding the command structure to accommodate the large number of fire fighters typically required at major high-rise incidents, safety, support functions, lobby and elevator control, and stairwell support. In addition, the issue of interagency coordination or mutual aid command procedures was only briefly mentioned in the SOPs. During the incident, the limitations in the SOPs and an apparent absence of any preplanning for large-scale incidents resulted in a lack of fire fighter accountability, considerable confusion in the incident command and staging areas, problems with the communications system, logistical difficulties, and coordination problems within the department and with the responding mutual aid units. In addition, the department's current system of equipping fire fighters with SCBA led to a shortage. Each department fire fighter was assigned an SCBA mask while the fire apparatus was equipped with a limited number of SCBA harnesses, air cylinders, and PASS devices. As a result, some fire fighters who responded to the general alarm reportedly did not have complete SCBAs to wear. Other problems that were encountered included the equipment incompatibilities between the responding department and the mutual aid units, the dissemination of information regarding the potential for exposure to hazardous materials such as asbestos and PCBs, and the lack of appropriate decontamination procedures. Investigators summarized the work practices as they affected the situation and provided recommendations to improve future responses. 


\section{DIESEL EXHAUST FXPOSURES}

Fire fighter exposures to diesel exhaust generally occur from trucks idling in the apparatus bays, which can allow exhaust to enter the offices and living quarters. Eight HHEs were conducted between 1990 and 2001 related to such exposure concerns. Recommendations were often for improved general dilution or local exhaust ventilation and for initiation of medical surveillance because of the nature of fire fighters' work.

Diesel exhaust is a complex mixture consisting of both gaseous and particulate fractions. The composition will vary greatly with fuel and engine type, maintenance, tuning, and exhaust gas treatment. 5,6 Gaseous constituents include $\mathrm{CO}_{2}, \mathrm{CO}$, $\mathrm{NO}_{2}, \mathrm{SO}_{\mathrm{x}}$, and hydrocarbons. The particulate fraction (soot) of diesel exhaust consists of solid carbon cores produced during combustion and compounds deposited on the particle cores through sorption and condensation processes. More than 95\% of diesel soot particles are less than $1 \mu \mathrm{m}$. Up to $65 \%$ of the total particulate mass may be these adsorbed substances. The majority of the adsorbed material is unburned fuel and oil, but trace levels of compounds such as PAHs are also present, some of which are carcinogenic. ${ }^{7}$ An estimated 18,000 substances from the combustion process can be adsorbed onto the particle cores. ${ }^{7}$

Studies of rats and mice exposed to diesel emissions, especially the particulate portion, confirmed an association with lung tumors. ${ }^{7}$ Human epidemiology studies also suggest an association between occupational exposure to whole diesel exhaust and lung cancer. ${ }^{7}$ In addition to the carcinogenic potential, many other components of diesel exhaust have known toxic effects. These effects include pulmonary irritation from $\mathrm{NO}_{x}$, eye and mucous membrane irritation from $\mathrm{SO}_{2}$ and aldehyde compounds, and chemical asphyxiation from CO. Exposure criteria have been established for some of these compounds; however, OSHA has not established a PEL for whole diesel exhaust emissions. ACGIH ${ }^{\circledR}$ has proposed a TWA TLV® of $0.02 \mathrm{mg} / \mathrm{m}^{3}$ for diesel exhaust, measured as elemental carbon (EC). ${ }^{8}$ On the basis of findings of carcinogenic responses in exposed rats and mice, NIOSH recommends that whole diesel exhaust be considered a potential occupational carcinogen and that exposures be reduced to the lowest feasible concentration. ${ }^{6}$ In addition to the carcinogenic effects, eye irritation and reversible pulmonary function changes have been experienced by workers exposed to diesel exhaust. ${ }^{7,9,10,11}$

Assessing workers' exposures to diesel exhaust is difficult because of the complex makeup of the exhaust, uncertainty about which specific agent(s) may be responsible for the carcinogenic properties, and the presence of other fine aerosols (such as tobacco smoke particles). Measurements of some commonly found components of diesel exhaust have generally shown concentrations to be well below established exposure criteria. However, the use of EC holds promise as a selective measure of diesel particulate because the sampling and analytical method has a low LOD, diesel particulate contains a high percentage of carbon (80\% to $90 \%)$, and there are few interferences. While the ACGIH ${ }^{\circledR}$ has proposed a TWA TLV® of $0.02 \mathrm{mg} / \mathrm{m}^{3}$ for diesel exhaust, measured as EC, NIOSH is continuing to investigate its use as a surrogate index of the particulate fraction. ${ }^{12,13}$ Although neither NIOSH nor OSHA have established numerical exposure limits, sampling for EC can provide information for assessing the effectiveness of diesel exhaust controls. 
HETA 90-0396

October 1990

Requester: Government

Purpose: To address concerns about fire fighter exposures to diesel exhaust in the living quarters and leukemia

Keywords: SIC 9224 (fire departments), fire-fighting, leukemia, diesel exhaust, SCBA tank air

Abstract: A NIOSH investigator conducted a walkthrough investigation of a fire department in response to a request from the Fire Chief expressing concerns about diesel exhaust in the living quarters. The concerns were heightened after the recent death of an employee from leukemia. A previous HHE had been conducted at this station in 1982, and several changes had been made based on the recommendations. Vents were opened to supply fresh air to the living quarters, the living quarters were under positive pressure with respect to the apparatus floor, morning vehicle starts were no longer performed, vehicles were parked outside for routine maintenance, the duct work was cleaned, a humidifier was installed in the sleeping quarters, and regular maintenance was performed on the humidifiers, furnace, and the air-handling system. Since all of these changes had been made, interviewed fire fighters stated that they did not smell exhaust in the living quarters, and air velocity measurements showed that air flowed from the living quarters to the apparatus bay, the NIOSH investigator concluded that further testing was not needed. Recommendations included the continuation of routine air-handling system maintenance and the initiation of a medical surveillance program because of the nature of fire fighters' work.

\section{HETA 92-0160-2360 October 1993}

Requester: Joint

Purpose: To evaluate exposure to diesel exhaust emissions

Keywords: SIC 9224 (fire departments), fire-fighting, fire fighters, diesel, elemental carbon, benzene solubles, carbon monoxide, $\mathrm{CO}$, nitrogen dioxide, $\mathrm{NO}_{2}$
Abstract: NIOSH conducted an HHE at three engine houses of a city fire division in response to a joint request from the Division of Fire and the local union to evaluate exposure to diesel exhaust emissions. Air samples for components of diesel exhaust emissions were collected from the evening through early morning on 2 days to evaluate exposures during a typically busy shift. NIOSH investigators visited the engine houses a second time to obtain data used to formulate the engineering control recommendations. PBZ air samples for EC, a surrogate for diesel exhaust, were also collected. GA air samples for EC, CO, benzene-solubles, and $\mathrm{NO}_{2}$ were collected at all three engine houses. In addition, a GA air sample for EC was collected outside each engine house and away from sources of diesel emissions to measure the concentration of ambient EC. In Engine House 1, PBZ samples for EC ranged from 14.1 to $71.2 \mu \mathrm{g} / \mathrm{m}^{3}$. In Engine House 2, they ranged from 19.8 to $78.8 \mu \mathrm{g} / \mathrm{m}^{3}$. In Engine House 3, they ranged from 24.0 to $60.5 \mu \mathrm{g} / \mathrm{m}^{3}$. The average background EC concentration measured on the first night of sampling was $12.1 \mu \mathrm{g} / \mathrm{m}^{3}$, and the average on the second night of sampling was $8.4 \mu \mathrm{g} / \mathrm{m}^{3}$. With the exception of one measurement of $4.6 \mathrm{ppm}$ of $\mathrm{CO}$ measured in the smoking room of Engine House 2 on the first night of the survey, only trace amounts of $\mathrm{CO}$ were detected in any of the other samples. During the 2 nights of sampling, benzenesolubles were only detected in one sample in Engine House 1 (on the second night in the large apparatus bay). This 686-minute sample yielded a concentration of $313 \mu \mathrm{g} / \mathrm{m}^{3}$. Since none of the vehicles were moved on the second night, the source of benzene-solubles in this sample was not clear. Benzene-solubles measured in Engine House 2 ranged from less than the LOD to $313 \mu \mathrm{g} / \mathrm{m}^{3}$. Sampling for benzene-solubles in Engine House 3 did not result in any concentrations in excess of the LOD for the method, $0.05 \mathrm{mg}$ per sample on either night. Since limited epidemiological evidence suggests an association between occupational exposure to diesel exhaust emissions and lung cancer, engineering controls and work 
practices to reduce the potential risk to fire fighters from diesel exhaust emission exposures were provided.

\section{HETA 92-0225 \\ September 1992}

Requester: Management

Purpose: To determine the potential exposure to diesel exhaust among paramedics at three hospital ambulance stations, one of which shares a building with a fire department

Keywords: SIC 8062 (hospitals), carbon monoxide, nitrogen dioxide, nitric oxide

Abstract: A hospital Environmental Health and Safety Manager requested an HHE to determine the potential exposure to diesel exhaust among paramedics at three hospital stations. One of the paramedic stations shared a building with the fire station that had installed a new ventilation system to control diesel exhaust. The system consisted of a local exhaust hose that connected directly to the vehicle exhaust pipe. When the vehicle left the garage, the hose slid along on a ceiling mounted track until it contacted a stop and disengaged from the exhaust pipe. The connection had to be manually reestablished when the vehicle returned to the garage. EC sampling showed that the new ventilation system was effective in reducing diesel exhaust exposures, and the NIOSH investigator recommended its use. The system did not affect the concentrations of $\mathrm{NO}_{\mathrm{x}}$, which were all very low. Similarly, CO concentrations were low, except at the southside station, where concentrations ranged up to $13 \mathrm{ppm}$. The NIOSH investigator recommended that the CO source be determined-gas water heater, ambulance, or other gas appliances-and then eradicated.
HETA 92-0384 November 1990

Requester: Management

Purpose: To assess exposures to diesel exhaust in seven fire stations with varied ventilation systems

Keywords: SIC 9224 (fire departments), diesel fumes

Abstract: At the request of a city fire department, NIOSH investigators visited four of its seven stations, two of which had added dilution ventilation systems, which the fire fighters had reported were inadequate for controlling diesel exhaust emissions. The investigators measured dimensions and flow rates at each station and educated the fire fighters about the different ways for controlling diesel emissions. They recommended the installation of tailpipe exhaust systems and the improvement of several work practices, such as opening the garage doors before starting the trucks, minimizing vehicle operation inside the station, and keeping doors to other areas closed and properly sealed. They also recommended maintaining the living and office areas at positive pressure with respect to the garage and keeping a record of health symptoms and nuisance complaints related to diesel emissions as an indicator of the need for future improvements.

\section{HETA 97-0304-2695 June 1998}

Requester: Employee

Purpose: To assess diesel exhaust exposure at fire stations throughout the city

Keywords: SIC 9224 (fire departments), fire-fighting, fire fighters, diesel, elemental carbon, nitrogen dioxide

Abstract: NIOSH received a request from fire fighters of a city fire department to conduct an HHE of diesel exhaust exposure at fire stations throughout the city. Health concerns included headaches and the possible carcinogenic risk associated with 
exposure to diesel exhaust. NIOSH investigators conducted an IH evaluation at two fire stations. Environmental monitoring was conducted for components of diesel exhaust including $\mathrm{NO}, \mathrm{NO}_{2}, \mathrm{EC}$, and miscellaneous hydrocarbons. PBZ and GA air samples were collected for EC at each station. Area samples were collected in the kitchen, apparatus bay, and in the fire fighters' sleeping quarters. Additionally, one background EC sample was collected outside of each station as a comparative measure. Exhaust ventilation flow rates were also measured to estimate air changes per hour in apparatus bays. EC was ND in all of the samples collected at station 5 on either night, indicating that the EC concentration for all area and PBZ samples (including background) was less than $4 \mu \mathrm{g} / \mathrm{m}^{3}$. Five of the $12(42 \%) \mathrm{EC}$ samples collected at station 8 were greater than background. These included two area samples collected in the apparatus bay and three PBZ samples. The highest EC concentration of $16 \mu \mathrm{g} / \mathrm{m}^{3}$ was measured in the apparatus bay. Concentrations of $\mathrm{NO}_{2}$ and $\mathrm{NO}$ in the stations were below exposure limits for these chemicals. Only low levels of contaminants were detected at each station by qualitative organic vapor screening. Compounds detected included toluene, isooctane, benzene, C6-C16 aliphatic hydrocarbons, MTBE, hexylene glycol, trimethylbenzenes, and naphthalenes. Air concentrations on the thermal desorption tubes were estimated to be less than $0.5 \mu \mathrm{g}$ for any single component (less than $0.07 \mathrm{ppm}$, based on the minimum sample volume). Analyses of charcoal tubes for benzene, toluene, and xylenes identified trace ( $<0.07 \mathrm{ppm})$ quantities of xylenes in two samples and did not detect benzene or toluene in any samples. The samples in which xylene was detected were collected during a 62-minute sampling period while the rescue unit left and returned to the station. Exposure to individual constituents of diesel exhaust was below respective NIOSH RELs at both stations, indicating that under the sampling conditions, these constituents should not pose a significant health hazard. Diesel exhaust in station 8 was confined to the apparatus bay. Three factors could be credited for the low diesel exhaust concen- trations at the time of the evaluation. First, the newer engines operated more efficiently and, consequently, generated cleaner exhaust than the older engines they replaced. Second, during the survey, stations 5 and 8 may have responded to fewer than the typical number of calls. Third, the ventilation is effectively removing exhaust from the bays. Recommendations were made that could further reduce diesel exhaust exposure.

\section{HETA 98-0152-2729 March 1999}

Requester: Government

Purpose: To conduct an evaluation of diesel exhaust exposure at a city Public Safety Building

Keywords: SIC 9224 (fire departments), fire-fighting, fire fighters, diesel, elemental carbon, nitrogen dioxide

Abstract: NIOSH received an HHE request from a State Department of Labor to conduct an evaluation of diesel exhaust exposure at a city Public Safety Building. The request indicated that fire and police personnel were exposed to diesel exhaust from fire apparatus. Asthmatic bronchitis was listed as a health problem resulting from this exposure. NIOSH conducted an IH evaluation that included air sampling for EC and $\mathrm{NO}_{2}$. With the exception of the 199minute EC sample collected in the apparatus bay $\left(0.009 \mathrm{mg} / \mathrm{m}^{3}\right)$, EC concentrations were below the MDC throughout the building. An $\mathrm{NO}_{2}$ concentration of $0.086 \mathrm{ppm}$ was measured over a 189-minute period in the apparatus bay. TWA $\mathrm{NO}_{2}$ sampling in other areas of the building revealed concentrations below the MQC. Direct-read (grab) measurements, however, appear to indicate that higher $\mathrm{NO}_{2}$ concentrations (peak concentrations) may occur in the apparatus bays during very brief periods when vehicles are entering or returning. It seemed likely that the concentration of diesel exhaust and its constituent compounds in the building varied, depending upon the operating conditions (e.g., engine temperature, tune-up condition, etc.), the type and size of engine, and the 
length of time that an engine ran in or near the building. Weather conditions may have also affected indoor concentrations of diesel exhaust by changing the pressure differential between the apparatus bay and other parts of the building, thus driving contaminants into occupied indoor areas. Although exposure to individual constituents of diesel exhaust was below respective NIOSH RELs, complaints of diesel exhaust in the building were likely to reoccur as long as diesel-powered emergency vehicles were present and fire and police staffs occupied adjacent offices and living areas. Investigators suggested that engineering controls be considered to alleviate comfort and health concerns, especially among persons who were more sensitive to the presence of diesel exhaust, such as asthmatics.

\section{HETA 99-0094 April 1999}

Requester: Union

Purpose: To assess exposures to $\mathrm{CO}$ and diesel exhaust in a local fire department Keywords: SIC 9224 (fire departments), fire-fighting, fire fighters, diesel exhaust, carbon monoxide

Abstract: A NIOSH investigator conducted a site visit along with a State Department of Labor representative, who had received a request for assistance from a local fire department concerning $\mathrm{CO}$ exposures from the oil furnace and diesel exhaust exposures from the fire trucks. The fire department dispatch center, day room, and apparatus bays were housed in an addition to the town offices building. Employees reported that the oil furnace had intermittent ignition problems that caused the furnace to release smoke and CO into the building. Six of the seven fire apparatus were diesel-powered, and the apparatus bays were not equipped with any local exhaust ventilation. Investigators observed pressure differentials between different areas in the fire station and conducted air sampling during four response simulations. Negligible air exchange between the bays and adjacent day room occurred, but the air flow in the suspended ceiling above the Board of Health office was from the apparatus bays. The highest $\mathrm{CO}$ concentrations were measured during simulated responses; a 20-minute TWA of 39 ppm was measured in the bays, and the peak was $108 \mathrm{ppm}$. The 20-minute $\mathrm{CO}$ concentrations in the adjacent day room and Board of Health office were 10 ppm and $4 \mathrm{ppm}$, respectively, with peaks of $12 \mathrm{ppm}$ and $6 \mathrm{ppm}$. An hour and a half after the simulations concluded, measurable concentrations of $\mathrm{CO}$ were still in these rooms. Concentrations of $\mathrm{NO}_{\mathrm{x}}$ were estimated to be $6 \mathrm{ppm}$ in the apparatus bays and $1.5 \mathrm{ppm}$ in the day room at the conclusion of all four simulations. It was noted that a few of the trucks had air leaks which prevented the brakes from releasing immediately upon startup. This resulted in an extra minute or so of diesel exhaust release in the bays. Also, a dieselpowered emergency generator that was used weekly was located a few feet from the back of the building. The State provided data indicating that the indoor $\mathrm{CO}_{2}$ concentrations were in the range of 800 to 900 ppm, showing inadequate ventilation and that other indoor contaminants may also build-up. Several recommendations were made to reduce the migration of diesel exhaust into the other areas of the building, such as minimizing idling times, performing regular engine tune-ups, repairing air leaks in the brake systems, keeping doors closed and properly sealed, maintaining a positive pressure differential with respect to the bay, scheduling generator weekly start-ups during periods when the building is unoccupied, and inspecting and maintaining the furnace. If these efforts were ineffective, then tailpipe exhaust ventilation systems could be added. 
HETA 99-0266-2850

May 2001

Requester: Management

Purpose: To evaluate the effectiveness of new diesel exhaust filtration controls

Keywords: SIC 9224 (fire protection), diesel exhaust control, fire stations, ceramic filters, elemental carbon

Abstract: NIOSH received an HHE request from a fire department that was planning to install diesel exhaust filtration systems on some of their apparatus and wanted NIOSH to evaluate the effectiveness of the controls. In response to the request, NIOSH conducted pre- and post-control evaluations of diesel exhaust in two fire stations. The pre-control evaluations were conducted on November 8-1 1, 1999. Samples were collected to characterize contaminant concentrations at the fire stations, and to provide base-line data for determining the effectiveness of the ceramic exhaust filters at controlling these contaminants. Airborne concentrations of $\mathrm{EC}, \mathrm{SO}_{2}, \mathrm{NO}, \mathrm{NO}_{2}$, and VOCs were measured. After the ceramic filters were installed on the engines, a follow-up evaluation was conducted on March 14-17, 2000, to determine the control's effectiveness in reducing diesel soot (measured as EC) in the fire stations.

In the initial survey, only trace concentrations of EC were measured in PBZ samples at each station. Concentrations of EC in the living quarters of each station were mostly in the ND to trace range as well. The 12 EC area samples collected in the apparatus bay of each station had mean concentrations of $6.1 \mu \mathrm{g} / \mathrm{m}^{3}$ in station 3 , and $15.6 \mu \mathrm{g} / \mathrm{m}^{3}$ in station $5 . \mathrm{SO}_{2}$ was not detected in any spot samples collected in the apparatus bay of either station. This indicates that the concentration of $\mathrm{SO}_{2}$ in the bay did not exceed 0.1 ppm as the apparatus entered and departed the station. NO concentrations in the apparatus bay of both stations were all below the MDC. This indicates that all concentrations were below 0.5 ppm as an 8-hour TWA, which is well below the current evaluation criteria. Low concentrations of several organic chemicals were identified. Identified chemicals included methyl t-butyl ether, $\mathrm{C}_{4}-\mathrm{C}_{7}$ alkanes, benzene, toluene, and xylenes. Concentrations of benzene and xylene were quantified and were well below current exposure criteria.

In the post-control evaluation, EC was not detected on 12 of 16 area samples collected in the bay of station 3 . Four area samples had a trace amount of EC, indicating that EC concentrations in the bay were between the MDC of $1.3 \mu \mathrm{g} / \mathrm{m}^{3}$ and the MQC of $5.1 \mu \mathrm{g} / \mathrm{m}^{3}$. EC was not detected on 11 of 16 area samples collected during the post-control sampling campaign at station 5 . Trace concentrations of EC were detected in four area samples, indicating that EC concentrations for these samples ranged from 1.3 to $5.1 \mu \mathrm{g} / \mathrm{m}^{3}$. A significant reduction in geometric mean EC concentrations in the apparatus bay of both stations was evident in the data. The reductions were $76 \%$ in station 3 and $91 \%$ in station 5 .

Thus, the NIOSH environmental assessment of diesel exhaust in two fire stations found that concentrations of diesel exhaust gas-phase components were low prior to the installation of engineering controls. Personal exposures to diesel exhaust particulate-phase components in these two fire stations were also low because the quantities of EC generated were moderate and because fire fighters and paramedics did not spend very much time in the apparatus bay. However, geometric mean concentrations of EC in the two bays were reduced by $76 \%$ and $91 \%$ after the ceramic diesel exhaust filters were installed. NIOSH researchers conclude that, in stations with pull-through apparatus bays, the ceramic filters are effective at reducing the emission of diesel soot. Recommendations were made for maintaining positive pressure in the living quarters relative to the bay and for a more formalized means of training and information exchange about engineering controls, should they be installed at other stations. 
NIOSH conducted five HHEs related to forest fire-fighting between 1990 and 1999. Each year, an estimated 80,000 wildland fire fighters fight approximately 70,000 forest fires that burn an average of 2 million acres of forested land. Forest fire smoke contains a wide variety of toxic components, many of which are pulmonary irritants, including particulates, formaldehyde, acetaldehyde, acrolein furfural, $\mathrm{SO}_{2}$, and acids. Wildland fire fighters may be exposed to smoke for long, uninterrupted periods. They typically work 12 hours per day, 6-7 days per week. The crew is usually transported by ground or air to and from staging areas. The duration of time that a fire fighter spends in travel during one shift can range from minutes to hours. After arriving at the staging area, crews may spend up to several hours hiking before initiating line construction.

There are two distinct classifications of wildland fires-prescribed and wildfire. A prescribed fire is designated as such when it is in the "prescription" of the burn. The prescription includes a specific geographic area and predetermined burning properties, such as flame height and fuel consumption. Conversely, a wildfire is a wildland fire that is outside of prescription. Although the strategies used to fight forest fires can vary dramatically, the techniques used from one fire to another are basically the same. Fire suppression relies on removing one or more of the three requirements of a fire: oxygen, fuel, and heat. For an uncontrolled fire, suppression efforts focus on removing the vegetation, which is the fuel for the fire. Procedures that remove heat and oxygen are relied on during the mop-up stage. Fire fighters use hand tools to remove vegetation, thus forming containment lines (also called firelines). When firelines are constructed adjacent to the fire, it is referred to as direct attack line construction. When they are constructed at a distance from the fire, it is referred to as indirect attack. While direct attack generally requires less time to control the fire, it usually requires personnel working nearer the heat and smoke. Air attacks, i.e., the dropping of water or fire retardant from various types of aircraft, are used to slow the progress of the fire and to extinguish spot fires. To remove fuels from areas ahead of the advancing fire, or to affect the direction or spread of the wildfire, unburned areas of land may be ignited intentionally within prescription. This is referred to as burning out or backfiring. Once the fire is controlled, fire fighters begin mop-up activities that include extinguising the fire completely with the use of hand tools, chain saws, dirt, and water and may involve digging up smoldering stumps, roots, and mineral soil and felling burning snags (a standing dead tree).

During suppression activities, a fire fighter typically wear Nomex ${ }^{\mathrm{TM}}$ pants and shirt, Vibrae-soled boots, hard hat, goggles, and leather gloves. (Nomex is a flame resistant, chemically treated material.) Some fire fighters also tie a bandanna across their nose and mouth in an attempt at respiratory protection. Fire-fighting crews involved in building a fireline by hand consist of approximately 20 crew members (typically 3 sawyers, 3 swampers who assist the sawyers, and the rest fire fighters who are equipped with hand tools). These crews are classified as either Type I or Type II crews. Type I crews, also referred to as "hotshots," are highly trained crews used primarily in hand fireline construction in direct attack. Type II crews are also used in hand fireline construction but are primarily relied on for mop-up activities. In 1987, smoke inhalation accounted for 38\% of all reported injuries and illnesses among all fire fighters in California. A CDHS study of 94 wildland fire fighters engaged in the Klamath National Forest fires of 1987 found that 76\% reported three respiratory symptoms (i.e., cough, wheezing, or shortness of breath). During the 1988 Yellowstone fires, $40 \%$ of the approximately 30,000 medical visits made by wildland fire fighters were for respiratory problems. This information suggests that wildland fire fighters experience significant rates of acute smoke inhalation. Many of the recommendations involved improved respiratory protection and/or respiratory symptom surveillance, as well as medical surveillance. 


\section{HETA 90-0365-2415 April 1994}

Requester: Government

Purpose: To characterize exposures and evaluate possible respiratory effects among forest fire fighters

Keywords: SIC 0851 (forestry services), forest fire-fighting, carbon monoxide, sulfur dioxide, extended work shifts, lung function tests, breath analysis, carboxyhemoglobin, respiratory symptoms, central nervous system symptoms

Abstract: NIOSH received an HHE request from the NPS to characterize exposures and evaluate possible respiratory effects among forest fire fighters at the Arch Rock Fire in Yosemite National Park, California. On August 15-16, 1990, NIOSH conducted IH and medical surveys on fire fighters belonging to three fire-fighting crews (two Type I and one Type II). The IH survey measured forest fire fighters' exposures to $\mathrm{CO}, \mathrm{SO}_{2}, \mathrm{NO}_{2}$, RPM, PAHs, VOCs, aldehydes, and acid gases. Also, samples of new and old bandannas (frequently used as respiratory protection by the forest fire fighter) were submitted for scanning electron microscopic analysis to measure the pore size of the fabric. The medical survey evaluated cross-shift changes in lung function, $\mathrm{CO}$ levels in exhaled breath (to estimate the COHb level), and irritant, respiratory, or CNS symptoms during one workshift.

The average $\mathrm{CO}$ and $\mathrm{SO}_{2}$ exposure concentrations measured in the breathing zone of the Pike Forest Hot Shots (fire fighters in the Pike forest) were 18.3 and $1.4 \mathrm{ppm}$, respectively. All $\mathrm{CO}$ measurements were below the NIOSH REL, the OSHA PEL, and the ACGIH ${ }^{\circledR} \mathrm{TLV}{ }^{\circledR}$; however, one of six air samples for $\mathrm{SO}_{2}$ was above the NIOSH REL of $2.0 \mathrm{ppm}$. The CO breathing zone exposure concentrations in the Plumas Forest Hot Shots averaged $3.9 \mathrm{ppm}$, and the average breathing zone exposure level for $\mathrm{SO}_{2}$ was $1.4 \mathrm{ppm}$, with one of the five air samples above the NIOSH REL of 2.0 ppm. $\mathrm{NO}_{2}$ was $\mathrm{ND}$ in the ten TWA air samples collected in the fire fighters breathing zones. The 35 ppm CO standard may not be appropriate for forest fire fighters. In developing the REL for CO, NIOSH used the $\mathrm{CFK}$ equation to determine the $\mathrm{CO}$ exposure level that would result in a COHb level less than $5 \%$ in most workers. Some of the variables (length of workshift, level of work activity, and altitude) used by NIOSH in the CFK equation were adjusted by the $\mathrm{NIOSH}$ investigators in this report to better describe the forest fire fighter's work environment. Using these new variables, the CFK equation predicts that a 5\% COHb level would be reached at an exposure concentration of $21 \mathrm{ppm}$. Ten (30\%) of the Pike Hot Shots and none of the Plumas Hot Shots had exposures in excess of $21 \mathrm{ppm}$. Low airborne concentrations of particulatebound acenaphthene, anthracene, and naphthalene, and gaseous acenaphthene, anthracene, fluoranthene, and benzo(b)fluoranthene were measured in the breathing zones of the fire fighters. In addition, low airborne concentrations of the following aldehydes and other VOCs were measured in the fire fighters' breathing zones: acetaldehyde, formaldehyde, acrolein, furfural, benzene, toluene, xylene, and total hydrocarbon compounds. The concentrations of hydrochloric acid, sulfuric acid, and hydrofluoric acid measured in the air samples for acid gases were also considered to be low. The exposure levels for RPM were below the OSHA PEL for RPNOR of $5 \mathrm{mg} / \mathrm{m}^{3}$. However, the OSHA PEL for RPNOR may not be applicable when evaluating exposures to this particulate matter since the dust contains particulate-bound PAHs. Scanning electron microscope pictures of the new and old bandanna samples demonstrated that the rectangular pore size of the fabric exceeded $100 \mu \mathrm{m}$ in both length and width, which would allow both respirable and inhalable particles to pass through the fabric and to enter the workers respiratory tract.

Overall, the mean cross-shift changes in lung function for the 21 participants were as follows: $-0.7 \% \mathrm{FVC},-1.2 \% \mathrm{FEV}_{1},-0.4 \%$ $\mathrm{FEF}_{25-75}$, and $-1.4 \% \mathrm{FEV}_{1} / \mathrm{FVC}$. The Type I crews had larger declines than the Type II crew in all spirometric values, and those for $\mathrm{FVC}, \mathrm{FEV}_{1}$, and $\mathrm{FEV}_{1} / \mathrm{FVC}$ were significant at the level of $P=0.05$ although each 
changed by $3 \%$ or less. The Type II crew had small cross-shift declines in $\mathrm{FEV}_{1}$, $\mathrm{FEV}_{1} / \mathrm{FVC}$, and $\mathrm{FEF}_{25-75}$, none of which were statistically significant at the level of $P=0.05$. The magnitude of the cross-shift declines in lung function did not appear to increase with self-reported increases in exposure. Overall the mean cross-shift increase in estimated $\mathrm{COHb} \%$ was $1.4 \%$ (95\% CI: $1.1 \%, 1.7 \%$ ). Cross-shift increase in $\mathrm{COHb} \%$ was not observed with increasing self-reported exposure to smoke. Crossshift symptom data were available on 10 participants from the Type II crew. The most frequent respiratory symptom developed during the shift was nose irritation; the most frequent CNS symptom was headache. The occurrence of respiratory or CNS symptoms was not associated with self-reported degree of exposure, but the validity of these findings is limited by the small number of fire fighters evaluated and self-estimates of exposure.

The NIOSH investigators concluded that a potential health hazard existed from exposure to $\mathrm{CO}$ and $\mathrm{SO}_{2}$ at the Arch Rock Forest Fires in Yosemite National Park. Their conclusion was based on the three CO exposure concentrations above the adjusted guideline of $21 \mathrm{ppm}$ and 2 of 11 exposure concentrations for $\mathrm{SO}_{2}$ above the NIOSH REL of $2.0 \mathrm{ppm}$. There was limited evidence of acute changes in lung function associated with activities of Type I crew members. Recommendations were made for respiratory protection and for a respiratory surveillance program to further examine the effects of forest fire-fighting on lung function.

\section{HETA 91-0152-2140 September 1991}

Requester: Government

Purpose: To determine whether wildland fire fighters incurred cross-season changes in lung function and respiratory symptoms Keywords: SIC 0851 (forestry services), forest fire-fighting, lung function tests, spirometry, respiratory symptoms
Abstract: NIOSH received an HHE request from the NPS to evaluate the health effects of forest fire smoke exposure among wildland fire fighters. In response to this request, NIOSH investigators conducted a medical survey of wildland fire fighters belonging to 6 hot shot crews in the NPS and the FS on June 11-15 and on September 24-28, 1990. The survey was conducted to determine whether wildland fire fighters incurred cross-season changes in lung function and respiratory symptoms during the 1990 fire season. During June 11-15, 1990, spirometry was performed and a questionnaire administered to 105 pre-season study participants (representing six hot shot crews) to establish a pre-season baseline. Post-season data were collected September 24-28, 1990, 15 weeks after baseline, on 78 individuals, representing $74 \%$ of the pre-season participants. All 78 individuals completed a post-season questionnaire and were retested by spirometry. The 6 crews were divided into 3 exposure categories (low, medium, high) on the basis of the total number of hours of fighting fires weighted by a visual estimate of the intensity of smoke at each fire. Overall, the mean cross-season changes for lung function for the 78 participants were $-0.5 \%$ (95\% CI: $-1.1 \%, 0.2 \%) \mathrm{FEV}_{1}$, $0.2 \%$ (95\% CI: $-0.5 \%, 0.9 \%$ ) FVC, $-2.3 \%$ (95\% CI: $-4.2 \%,-0.5 \%) \mathrm{FEF}_{25-75}$, and $-0.5 \%$ (95\% CI: $-1.0 \%,-0.1 \%) \mathrm{FEV}_{1} / \mathrm{FVC}$. Doserelated decreases in $\mathrm{FEF}_{25-75}$ and $\mathrm{FEV}_{1} / \mathrm{FVC}$ were observed with higher exposure (test for linearity: $P=0.08$ and $P=0.16$, respectively). Respiratory symptom prevalence did not increase significantly cross-seasonally and were not associated with exposure. The validity and applicability of these findings may be limited by several factors, including sample size, selection biases, and a nonrepresentative fire season. On the basis of this investigation, the NIOSH investigators concluded that there was limited evidence suggesting that forest firefighting results in cross-season changes in lung function. A respiratory surveillance program was recommended to examine the long-term effects of forest fire-fighting on lung function. 


\section{HETA 91-0312-2185 March 1992}

Requester: Government

Purpose: To collect information about the potential health effects from fire fighter's exposure to smoke during fire suppression activities at wildland fires

Keywords: SIC 0851 (forestry services), forest fire-fighting, carbon monoxide, sulfur dioxide, particulate matter

Abstract: NIOSH received an HHE request from the NPS. The purpose of the request was to collect information about the potential health effects from fire fighter's exposure to smoke during fire suppression activities at wildland fires. IH data were collected from July 20-22, 1991, during the Thompson Creek Fire in Gallatin National Forest. PBZ air samples were collected for $\mathrm{CO}, \mathrm{SO}_{2}$, aldehydes, RPM and respirable crystalline silica. The $\mathrm{CO}$ exposure levels ranged from ND to $17 \mathrm{ppm}$; these levels are below the evaluation criteria used by NIOSH, OSHA, and ACGIH®. $\mathrm{SO}_{2}$ concentrations ranged from 0.6 to $3.0 \mathrm{ppm}$. Three of the 26 PBZ samples were above the evaluation criteria of $2.0 \mathrm{ppm}$ used by NIOSH, OSHA, and ACGIH ${ }^{\circledR}$ for an 8-hour TWA. Aldehyde concentrations were an order of magnitude or more below the evaluation criteria used by OSHA and ACGIH ${ }^{\circledR}$. NIOSH considers acetaldehyde and formaldehyde to be potential occupational carcinogens and therefore recommends that exposures be reduced to the lowest feasible level. Of the 14 samples analyzed for respirable silica, one sample was above the OSHA and ACGIH ${ }^{\circledR}$ evaluation criteria for quartz. NIOSH considers silica to be a potential occupational carcinogen and therefore recommends that exposures be reduced to the lowest feasible level. The IH data collected during this survey suggested that a potential health hazard from $\mathrm{SO}_{2}$ exposure existed during fire suppression activities.

\section{HETA 92-0045-2260 October 1992}

Requester: Government

Purpose: To characterize fire fighters' exposures to chemical contaminants during wildland fire suppression operations

Keywords: SIC 0851 (forestry services), forest fire-fighting, carbon monoxide, sulfur dioxide, aldehydes, volatile organic compounds, crystalline silica, benzene

Abstract: NIOSH received an HHE request from the NPS. The purpose of the HHE was to characterize fire fighters' exposures to chemical contaminants during fire suppression operations. IH data were collected on November 3-4, 1991, during the Gauley Mountain Fire at the New River Gorge National River in West Virginia. PBZ and GA air samples were collected to measure airborne concentrations of $\mathrm{CO}, \mathrm{SO}_{2}$, aldehydes, VOCs, RPM, crystalline silica, benzenesolubles, and PAHs. Eight-hour TWA exposures ranged up to $9 \mathrm{ppm}$ for both $\mathrm{CO}$ and $\mathrm{SO}_{2}$ with average exposures of 4 and 2 Ppm, respectively. CO exposures were well below the NIOSH REL of 35 ppm. Twentythree of the $40 \mathrm{PBZ}$ measurements of $\mathrm{SO}_{2}$ exposures were at or above the NIOSH REL of 2 ppm. Formaldehyde concentrations ranged up to $0.10 \mathrm{ppm}$. NIOSH considers formaldehyde to be a potential occupational carcinogen and recommends that exposures be reduced to the lowest feasible level. Air concentrations of other aldehydes detected (acetaldehyde, acrolein, and furfural) were below the MQC. VOCs were ND. Air concentrations of RPM ranged up to $1.5 \mathrm{mg} / \mathrm{m}^{3}$. Silica was ND. Air concentrations of benzene solubles ranged up to $0.67 \mathrm{mg} / \mathrm{m}^{3}$; however, PAHs were ND on these samples. Air concentrations of naphthalene measured from the tube portion of the PAH samples ranged up to $6.1 \mu \mathrm{g} / \mathrm{m}^{3}$. This is well below the NIOSH REL of $50 \mathrm{mg} / \mathrm{m}^{3}$. Concentrations of other PAHs were below the MQC. Results indicated that fire fighters were overexposed to $\mathrm{SO}_{2}$ during wildfire suppression activities. Recommendations for reducing $\mathrm{SO}_{2}$ exposures and for future collection of exposure data were provided. 


\section{HETA 98-0173-2872 \\ March 2000}

Requester: Government

Purpose: To field-test a wildland fire fighter smoke exposure management and monitoring program outlined in earlier National Wildfire Coordinating Group sponsored research

Keywords: SIC Code 0851 (forestry services) Wildland fire fighter, carbon monoxide, $\mathrm{CO}$, State health department, Colorado

Department of Public Health and Environment, CDPHE, National Wildfire Coordinating Group, NWCG, United States Forestry Service, USFS, Department of Interior, DOI, Bureau of Land Management, BLM

Abstract: NIOSH received a request from a State Department of Public Health and Environment to assist in a project to be conducted in cooperation with USFS and BLM personnel. The goal of the project was to field-test the implementation of a wildland fire-fighter smoke exposure management and monitoring program outlined in earlier NWCG sponsored research. The Department also hoped to provide further exposure data related to fuels in areas of the United States, other than the Pacific Northwest where much of the previous data had been collected. The Department asked NIOSH to train fire fighters in the use of CO dosimeters during wildland fires, and to assist in data collection when the USFS and BLM conducted fire-fighting activities during the 1998 fire season. Four crews of wildland fire fighters were equipped with $\mathrm{CO}$ monitors, related equipment for calibration and data transfer, and training for two people from each crew in the use of the monitors. The fire fighters monitored $\mathrm{CO}$ exposures from 0 to 176 hours (depending upon the crew) during the fire season. During 8 of the 41 monitoring periods, $\mathrm{CO}$ exposure concentrations exceeded the NIOSH REL of 200 ppm. During 10 of the 41 sessions, measured CO concentrations exceeded the $A C G I H \bowtie$ excursion limit of 125 ppm. TWA exposures were all within current occupational exposure limits. During 2 of the 41 periods (each 480 minutes in length), CO exposure concentrations of 21 and $22 \mathrm{ppm}$ were measured. These exposures approach the ACGIH ${ }^{\circledR}$ TLV ${ }^{\circledR}$ of $25 \mathrm{ppm}$. The data collected in this evaluation indicated that wildland fire fighters may be exposed to $\mathrm{CO}$ concentrations in excess of recommended ceiling/excursion limits during as much as $25 \%$ of their fire-fighting efforts. This project showed that managers and safety officers could establish exposure monitoring and control programs to aid in the reduction of fire fighter exposures to smoke components, given the proper financial and administrative support. Several issues needed further evaluation before such programs could be optimally effective. These issues included availability of equipment and training; consistent documentation of monitoring conditions among fire fighters; a written smoke exposure management plan containing a response strategy when $\mathrm{CO}$ monitors should alarm; health surveillance programs; and training and tactics to minimize exposures.

\section{CHEMICALFIRES}

In the 1980s, approximately 30 HHEs were conducted because of chemical fires, many of which involved electrical transformers. In the 1990s, only six such HHEs were done, and none involved transformers. Exposures and potential health effects will vary with each type of chemical fire, so a standard recommendation has been that fire fighters have special training and SOPs for hazardous materials responses.

\section{HETA 91-0190-2491 February 1995}

\section{Requester: Union}

Purpose: To assess the safety and health practices used during a response to a fire at an illegal dump site

Keywords: SIC 9224 (fire departments), fire-fighting, fire fighters, methylene chloride, dump fire

Abstract: NIOSH received an HHE request from the IAFF to assess the safety and health practices used during a response to 
a fire at an illegal dump site. The IAFF reported that more than 300 fire fighters and other response personnel were involved in the incident and that approximately 90 had reported chemical exposure injuries. In response to this request, NIOSH investigators conducted a site visit to the city fire department. Several meetings were held with representatives from several of the responding agencies, and a tour of the fire scene was conducted. Incident reports, air sampling results, medical records, and other pertinent reports from the responding agencies were reviewed. A copy of the ICS was also obtained for review. In addition, the EPA collected and analyzed samples of fire fighter turnout gear to address decontamination issues. The results of this analysis were provided to NIOSH for review. The fire suppression activities during this incident were hampered by high winds and several directional wind shifts. During the incident, several fire fighters reportedly did not wear their SCBA or depleted their supply of air cylinders. Air monitoring performed by the State Department of Environmental Protection during the incident indicated that methylene chloride may have been present in the smoke plume at concentrations reaching $400 \mathrm{ppm}$. Numerous fire fighters were treated on-site by the responding EMS for dizziness, mucosal irritation, and elevated blood pressure. EMS personnel also noted abnormalities among several fire fighters on the field cardiac monitors. According to the EMS records, 171 fire fighters were transported to 8 area hospitals, and 3 were eventually admitted. However, the fire department report stated that 68 fire fighters received incident-related injuries. Representatives from the responding agencies indicated that there were several instances of coordination and communication difficulties. These difficulties led to confusion concerning incident classification (debris fire or hazardous materials incident) and command structure (single versus unified). Other problems encountered included the exchange of information between responding agencies, the use of SCBAs by the fire fighters, the delegation of authority to deputies in areas such as incident safety, and the establishment of a staging area. The EPA analyzed the fire fighter turnout gear for the presence of metals, pesticides, herbicides, PCBs, dioxins, and PAHs. This analysis was performed to address decontamination issues; however, the results were inconclusive. On the basis of the information obtained during this investigation, the NIOSH investigators were unable to determine a definitive environmental cause for the adverse health effects experienced by numerous fire fighters during this incident, even though possible acute exposures to methylene chloride may have been a contributing factor. However, several limitations regarding the application of incident command and safety procedures were identified. Recommendations regarding these procedures were presented in the report.

\section{HETA 91-0230-2543 November 1995}

\section{Requester: Union}

Purpose: To evaluate the safety and health practices followed by county and city fire departments in response to a chlorine leak from a nearby chlor alkali plant

Keywords: SIC 9224 (fire departments), fire fighters, chlorine, respiratory symptoms, police, incident command system, health effects, self-contained breathing apparatus

Abstract: NIOSH received a request for an HHE from the IAFF on behalf of members of a county and a city fire department. Fire fighters in these departments responded to a chlorine leak at a chlor alkali plant located just outside the city limits. The IAFF reported that several fire fighters who responded to this incident had developed respiratory symptoms that they attributed to chlorine exposure. Three weeks after the incident, NIOSH investigators held joint meetings with representatives from the management of both fire departments, the city, and the two IAFF local unions. In addition, separate meetings were conducted with representatives of the county health district and the chemical plant. Private interviews were conducted with 10 city fire fighters and the physicians who treated fire fighters during and after the incident. 
Information from these meetings, various records, and interviews were used to reconstruct events and procedures used during the incident response and to review incident medical care and fire fighter symptoms. According to available records, approximately 200 fire fighters were involved in the response to this emergency. Eleven fire fighters were hospitalized or held for observation, and several others were reportedly injured by exposure to the chlorine. Many of the fire fighters complained of skin irritation and respiratory difficulty, even though they were wearing SCBAs and structural fire fighter's protective clothing. Although a CAER plan had previously been devised by the chemical manufacturers at the industrial complex where the plant was located and the local emergency response units, this plan was reportedly not activated. Air monitoring performed by the county health district indicated that chlorine concentrations during the incident ranged from less than 0.2 to $17 \mathrm{ppm}$. Because of the weather conditions, the chlorine plume was unpredictable, and the command post had to be relocated on four occasions.

Representatives from the responding agencies indicated several instances of coordination and communication difficulties. Reported concerns and problems encountered during the incident response included delays in the response of the hazardous materials teams, deployment and use of appropriate PPE, lack of a common communications frequency for all participating agencies, and lack of appropriate decontamination procedures.

Six months following the chlorine leak, 150 medical questionnaires were sent by mail to the involved police and fire departments for completion by workers potentially exposed during the incident. NIOSH received a total of 59 completed questionnaires: 42 from fire fighters and 17 from individuals other than fire fighters. Most fire fighters responding to the questionnaire reported inhaling chlorine gas, even though most used respirators during the incident. Symptoms included coughing, tightness in the chest, wheezing, tearing eyes, sore throat, or headache after exposure to chlo- rine. Among the questionnaire respondents, symptom occurrence and severity were greatest among those stationed at the leak site. The duration of symptoms also appeared to increase with proximity to the chlorine leak. Symptom resolution was faster among respondents who wore respirators, which may suggest that the intensity of exposure experienced, the personal perception of respirator need, and improper respirator use were related to symptom duration. Several fire fighters who responded to this incident experienced adverse health effects from chlorine gas exposure, including hospitalization and persistent respiratory symptoms. Many of the fire fighters complained of skin irritation and respiratory difficulty, even though they had worn SCBAs and their structural fire fighter's protective gear. The questionnaire data indicated that the duration and severity of respiratory symptoms tended to increase with the proximity to the leak site, despite the use of respirators. However, the low response rate to the questionnaire survey and potential selection biases limited the ability to further generalize the questionnaire data. Possible explanations for the occurrence of symptoms included the improper fit of, or delays in donning of, respiratory protection and the use of structural fire-fighter's protective gear instead of appropriate chemical protective clothing. Recommendations regarding the appropriate kind of response to this type of incident were made.

\section{HETA 95-0047-2485 February 1995}

Requester: Employee

Purpose: To investigate the circumstances of a hazardous materials incident that occurred at a correctional institute Keywords: SIC 9224 (fire departments), fire-fighting, fire fighters, chlorine, hazardous materials

Abstract: NIOSH DSR received a request from employees to investigate the circumstances of a hazardous materials incident that occurred at a correctional institute that operates a chemical plant on its grounds. 
The local fire department had been called to respond to a vapor cloud that resulted from improper mixing and storage of powdered laundry bleach. The fire fighters requested technical assistance from $\mathrm{NIOSH}$ in reviewing both general and specific issues relating to this hazardous materials emergency response, especially regarding ICS, personnel training, chemical protective clothing, trained and equipped backup personnel, medical evaluations, and decontamination procedures. NIOSH recommended that when chemicals are being measured and mixed at the chemical plant, the facility manager or a supervisor should always be present, that the fire department should develop written SOPs for hazardous materials responses, that fire fighters should be kept up-to-date for hazardous materials responses, and that fire fighters should receive routine medical evaluations.

\section{HETA 97-0034-2683 April 1998}

Requester: Joint Union and Management Purpose: To review fire suppression and overhaul activities, evaluate the overall incident command structure, and investigate chemical exposures and injuries experienced by fire fighters during a chemical warehouse fire

Keywords: SIC 9224 (fire departments), fire-fighting, fire fighters, industrial fire, chemical fire, chemical warehouse, incident command system, ICS, health effects, selfcontained breathing apparatus, SCBA, PPE, contamination, overhaul

Abstract: NIOSH received an HHE request from the local IAFF on behalf of 78 fire fighters involved in a chemical warehouse fire. Fire fighters dispatched to the fire scene experienced chemical exposures and injuries. NIOSH was asked to provide technical assistance in reviewing the circumstances surrounding fire suppression and overhaul activities, to evaluate the overall incident command structure, and to investigate chemical exposures and injuries experienced by the fire fighters. Records were reviewed for 19 fire fighters who experienced acute health effects during and after fire suppression; these health effects included frequent headaches, chemical burns, irritation on face and hands, nose bleeds, cough, and a metallic taste in the mouth. Injuries experienced by two other fire fighters included a fractured pelvis and a concussion. Numerous reports and notes from the fire department's safety and health office, the Fire Investigation Unit, the local health department, and a local hospital were collected and later reviewed. Some fire fighters were interviewed (confidentially) in person and others were interviewed by telephone to gather additional details of the incident. Deficiencies that contributed to injuries and illnesses were identified.

Response activities, including medical care and monitoring, were reviewed to reconstruct events both during and after the fire incident. On the basis of the information obtained and reviewed, NIOSH investigators concluded that a variety of acute symptoms experienced by fire fighters were associated with occupational exposures in the course of fire suppression. Skin irritation temporarily associated with the use of equipment previously used at the chemical fire could be due to residual chemical contamination of the equipment.

Recommendations were offered to address safety and health deficiencies of the overall ICS and activities and to improve the medical evaluation system for the fire fighters.

\section{HETA 99-0062-2804 February 2000}

\section{Requester: Union}

Purpose: To assess the incident response procedures followed during a fire in a refuse waste-to-energy facility

Keywords: SIC 9224 (fire protection), fire fighters, incident command system, ICS, self-contained breathing apparatus, SCBA

Abstract: NIOSH received a request from IAFF to assess the incident response procedures followed during a fire in a refuse waste-toenergy facility. On December 17, 1998, the responding fire department received a report of a fire in the refuse pit of a refuse waste-to-energy facility. The fire was 
declared a hazardous materials incident as information became known that the fire had involved chlorine bleach cleaner which, according to the product's MSDS, would liberate chlorine and phosgene as decomposition products. Fire fighters used the plant's showering facilities for decontamination purposes before all of the 37 responding fire fighters were sent to area hospitals for evaluation. The IAFF indicated that several of the fire fighters responding to the incident were subsequently hospitalized due to smoke and chlorine gas inhalation. NIOSH investigators conducted a site visit in April 1999, and again in June 1999. NIOSH personnel conducted private interviews with several fire fighters who responded to the incident and reviewed several incident-related records, including the department's SOPs and medical records. Self-administered questionnaires were distributed to fire fighters who were not present on the days of the NIOSH investigation. In addition to the medical interviews and questionnaires, medical records were reviewed from five hospitals where the fire fighters received medical care, and from the occupational medicine provider. NIOSH investigators also visited the refuse waste-to-energy facility.

The medical survey showed that most fire fighters at the scene experienced some degree of acute upper respiratory tract irritation, and many experienced lower respiratory tract irritation as well. Fifteen had persistent symptoms at 24 hours, and 13 had symptoms at the time of the NIOSH investigation. Based on the combustion of chlorine-containing cleaner, the fire fighters' exposures probably consisted primarily of irritant gases, such as chlorine and nitrogen trichloride. Medical records revealed that the treating physicians were aware that the fire fighters were exposed to chemicals at a fire and were concerned about the inhalation of toxic fumes and smoke. However, neither fire fighters nor treating physicians knew what specific toxins were present. The symptoms of the fire fighters were consistent in the different hospitals; however, the diagnostic tests performed differed. The university-based hospital performed the most diagnostic tests on the fire fighters. The other hospitals performed fewer tests, but this did not appear to result in a greater rate of adverse health outcomes.

The elements leading to the fire fighter exposures were complex and multi-factorial in nature. Clearly, fire fighters did encounter exposures to irritant gasses at the scene. The responding fire department approached the incident in fire mode, when in fact, a hazardous materials response approach would have been more appropriate. Most fire fighters suffered irritant symptoms that were the result of exposures to irritant gases. For those fire fighters who had recovered at the time of the NIOSH investigation or did not develop symptoms, it was unlikely that the exposure would result in further health problems. Those who developed more significant respiratory symptoms were being further evaluated by health care providers. Several recommendations were offered for improving fire fighter health and safety, including recommendations for better integration of fire fighter medical surveillance information with acute care occupational medicine providers, better PPE usage, and filling gaps in the hazardous materials response plan.

\section{HETA 2001-0043-2844 May 2001}

Requester: Union

Purpose: To assess the incident response procedures followed during a response to a plastics recycling plant

Keywords: SIC 9224 (fire protection), fire fighters, plastics fire, plastic, burning carpet, burning nylon, incident command system, rehabilitation, rehab, respiratory arrest, mucous membrane irritation, respiratory symptoms, constitutional symptoms

Abstract: NIOSH received a request to conduct an HHE at a city fire department that had to respond to a plastics recycling plant fire on October 1, 2000. On December 11-14, 2000, NIOSH investigators traveled to the site to conduct an incident and medical evaluation. The incident evaluation consisted of surveying the remaining structures at the fire ground, examining department policies and procedures, interviewing fire 
fighters who responded to the incident, and reviewing the following records: (1) department incident reports and witness statements, (2) the Bureau of Alcohol, Tobacco, and Firearms report, and (3) MSDSs of the primary fuel sources. The medical evaluation consisted of the following: (1) interviewing fire fighters who responded to the incident, (2) discussing the current health and safety program with the fire department's Emergency Medical Services Director, (3) reviewing the "first report of injury" forms associated with this incident, (4) reviewing injury reports from the on-scene Rehabilitation unit, (5) reviewing the responding ambulance and medical chart from the one hospitalized fire fighter, and (6) reviewing exposure monitoring conducted two days after the fire. The investigation revealed the following problems during the fire: staffing shortages, communication problems (radios not working and missed information), material shortages in the Rehabilitation area (air bottles and fluids), procedural deficiencies, lack of a pre-incident plan, and lax observance and enforcement of SCBA use. One fire fighter suffered a life-threatening emergency (unresponsive, elevated blood pressure, rapid shallow respirations, and sinus tachycardia) and other fire fighters reported mucous membrane irritation and respiratory symptoms consistent with, but not specific for, exposure to burning plastic. Other than one critical case and three less critical cases, no other fire fighters reported persistent symptoms.

A combination of communication problems, staffing and material shortages, and planning and procedural deficiencies, put the health and safety of fire fighters at risk. One fire fighter suffered a life-threatening emergency and other fire fighters reported mucous membrane irritation and respiratory symptoms consistent with exposure to smoke and burning plastic. It cannot be determined if any long-term health effects will result from smoke exposure at this particular fire. Mandatory annual medical evaluations and periodic medical examinations should be implemented for the entire department. Analysis of this data over time may allow the department to determine whether this or other large fires are associated with adverse long-term health effects.

\section{COMMUNIGABLE DISEASES}

Fire fighters are now often cross-trained as first-responders and emergency medical technicians, and communicable diseases have become a prominent concern in the fire service. In the past decade, NIOSH conducted two HHEs related to fire fighters and a communicable disease. Bloodborne pathogens, particularly $\mathrm{HCV}$, and $\mathrm{TB}$ are the most significant concerns, but fire fighters have the potential to be exposed to any communicable disease. Because of the nature of emergency response, typical engineering controls are not applicable. Therefore, proper work practices and prevention strategies must be identified and instituted. Guidance for determining these strategies can be found on the OSHA and CDC websites (www.osha.gov and www.cdc.gov) in the various documents related to TB, HIV, HBV, HCV, bloodborne pathogens, and health care personnel.

Because emergency and public-safety employees work in environments that provide inherently unpredictable risks of exposures to bloodborne pathogens, general infection control procedures should be adapted to these work situations. Since exposures are unpredictable, protective measures may be warranted in situations that initially do not appear to present risk. Emergency and public-safety workers perform their duties in the community under extremely variable conditions; thus, control measures that are simple and uniform across all situations have the greatest likelihood of worker compliance. Occupational exposures should be considered urgent medical concerns to ensure timely administration of postexposure prophylaxis if it is indicated. A broader overview of the modes of transmission of TB, HIV, HCV, and HBV is included in the documents listed in association with the above mentioned websites (www.osha.gov and www.cdc.gov).

An "emergency medical service" worker may include paramedics, fire fighters, emer- 
gency medical technicians, advanced life support personnel, and others performing medical services in the field. The following recommendations for an emergency response program were prepared based on information from the above listed references.

1. The program should cover all employees who could be reasonably anticipated, as the result of job duties, to contact blood or other potentially infectious materials. Potentially infectious materials include semen, vaginal secretions, cerebrospinal fluid, synovial fluid, pleural fluid, pericardial fluid, peritoneal fluid, amniotic fluid, any body fluid visibly contaminated with blood, and all body fluids in situations where it is difficult or impossible to differentiate between body fluids.

2. The program should include a written plan that identifies tasks, procedures, and job classifications in which occupational exposure to potentially infectious material occurs -without regard to personal protective clothing and equipment. The written plan should address all aspects of the emergency medical services infectious disease program. The plan must be accessible to employees and employee representatives. The employer should review and update the plan at least annuallymore often if necessary to accommodate changes or recommendations from appropriate agencies.

A work practices program should be established that includes SOPs for all activities having the potential for exposure. Once these SOPs are developed, initial and periodic worker education programs to assure familiarity with work practices should be provided to potentially exposed workers. No worker should engage in such tasks or activities before receiving training pertaining to the SOPs, work practices, and protective equipment required for that task.

3. The program should mandate universal precautions (all persons should be assumed to be infectious for bloodborne pathogens), emphasizing engineering and work practice controls. Washing of the skin following exposure to potentially infectious material should be stressed; the program should include provision of facilities or equipment to be used for washing and ensure that employees use them following exposure to potentially infectious material. The program should include procedures used to prevent needlesticks, minimize splashing and spraying of potentially infectious material, and ensure appropriate disinfection or disposal of contaminated clothing or equipment.

a. As a part of the program, the City should provide, at no cost, and require employees to use, appropriate PPE such as gloves, gowns, masks, mouthpieces, and resuscitation bags.

b. All work activities should be classified into one of three categories of potential exposure: (i) activities with direct contact with blood or other body fluids to which universal precautions apply, (ii) activities usually performed without exposure to potentially infectious material, but exposure may occur in emergency, and (iii) activities that do not entail exposure to blood or other potentially infectious material. Employers should make protective equipment available to all workers when they are engaged in Category I or II activities.

c. Regarding personal protective or other equipment, the program should do the following: (i) include a plan for cleaning or disposal of equipment or clothing that has come into contact with blood or other potentially infectious materials, identifying the method of decontamination (if appropriate) to be used, (ii) specify methods for disposing of contaminated sharps, and (iii) include a plan for use of appropriately labeled containers for potentially infectious material.

4. The program should make TB testing and HBV vaccination available to all employees who have occupational 
exposure to potentially infectious material. For personnel at ongoing risk for exposure to blood or other potentially infectious material, follow current recommendations for postvaccination screening.

5. The program should include a current plan for post-exposure evaluation and follow-up for all employees who have had an exposure incident. Occupational exposures should be considered urgent medical concerns to ensure timely administration of postexposure prophylaxis. Studies by CDC have suggested that the recommended HIV post-exposure prophylaxis, when determined to be appropriate by a qualified physician, is most effective when started within 2 hours of exposure. Employers with employees at risk of exposure should have protocols that promote prompt reporting and facilitate access to post-exposure care. An algorithm is provided in CDC guidelines to guide clinicians and exposed workers in deciding when to consider postexposure prophylaxis.

6. All laboratory tests should be conducted by an accredited laboratory at no cost to the employee.

7. All laboratory tests and diagnoses should remain confidential. That is, medical care providers should inform the Fire Department of any necessary accommodations or work restrictions but not specific test results or diagnoses.

8. The program should include training concerning all aspects of the emergency medical services infectious disease program. Training should include general discussion on TB, bloodborne diseases, and their transmission; the written exposure control plan; engineering and work practice controls; PPE; HBV vaccine; response to emergencies involving blood; how to handle exposure incidents; the postexposure evaluation and follow-up program; and signs/labels/color-coding to alert persons to potentially infectious material. There should be opportunity for questions and answers, and the trainer should be knowledgeable in the subject matter.

9. The program should require that medical records for each employee with occupational exposure be kept according to any standards that may apply by law for that jurisdiction, or for the duration of employment plus 30 years, whichever is longer. The records should be kept in a confidential manner. Medical records should be made available to the subject employee or anyone with written consent of the employee. They are not routinely available to the employer. Training records should be maintained for 3 years.

\section{HETA 95-0072 March 1996}

Requester: Union

Purpose: To assess the potential occupational risk of TB to fire fighters in a city fire department

Keywords: SIC 9224 (fire departments), fire-fighting, fire fighters, Mycobacterium tuberculosis, tuberculosis, TB, tuberculin skin test, TST

Abstract: The IAFF requested an HHE to assess the potential occupational risk of TB to fire fighters in a city fire department where 135 of 1,112 (12\%) had a positive TST between January 1990 and November 1994. Since only active TB cases, not positive TSTs, are reported to State health departments, a background TST prevalence was not available for the city. NIOSH investigators could not determine the extent of the risk of occupationally acquired TB infection among the city fire department personnel for several reasons, including the lack of a two-step TST upon first employment, the lack of documentation of negative reaction sizes, discrepancies in at least two employee's results, and the fire department's different definition of a conversion. However, it was noted that the TB prevention program had greatly improved in the past year. Although the department's 
respiratory policy was consistent with the OSHA respiratory protection standard, it relied on individual fire fighters to determine whether a situation warranted respirator use. Fire fighters generally did not have a clear idea of a patient's TB status, and some were reportedly resistant to respirator use because of discomfort and impaired communication with the patient. Also, no current ventilation criteria for ambulances that addressed the issue of infectious disease transmission existed. The NIOSH investigator provided many recommendations to improve the TB testing and prevention program, including strengthening the TB testing program, assuring effective employee training, and providing effective respiratory protection procedures.

\section{HETA 2000-0056 September 2000}

Requester: Union

Purpose: To assess the potential occupational risk of HCV infection among fire fighters in a city fire department Keywords: SIC 9224 (fire departments), fire-fighting, fire fighters, hepatitis $\mathrm{C}, \mathrm{HCV}$, first responders, emergency medical personnel, bloodborne pathogens

Abstract: The IAFF requested an HHE to assess the potential occupational risk of HCV infection among fire fighters in a city fire department. NIOSH investigators spoke with several union and city representatives, reviewed the fire department health and safety records pertaining to infectious diseases, provided information from current literature and guidelines, and made recommendations for updating the current communicable disease program.

Specific needs for such a program were outlined as in the introduction to this section.

\section{OTHER}

\section{HETA 91-0370 January 1992}

Requester: Union

Purpose: To determine if there was an occupational source of arsenic to which fire fighters may be exposed

Keywords: SIC 9224 (fire departments), arsenic

Abstract: An IAFF local requested an HHE to determine if the diagnosis of arsenic poisoning in one fire fighter could be workrelated. The NIOSH investigator (1) collected background information and surface wipe samples at the fire station and from the fire fighter's personal turnout gear,

(2) visually inspected the fire stations, (3) interviewed the affected fire fighter, the analytical laboratory that detected the excess levels of arsenic, and the diagnosing physician, and (4) obtained the most recent water quality analysis from the city. No arsenic sources were identified, and no arsenic was detected except for trace amounts on a wooden work bench, which could have originated from a variety of sources, including treated lumber or pesticides. Since fire-fighting is not considered an occupation that poses a risk of overexposure to arsenic and no exposure sources were identified, the NIOSH investigator recommended additional biological monitoring to differentiate between dietary and environmental arsenic. 
HETA 99-0299

January 2001

Requester: Government

Purpose: To provide technical assistance in evaluating potential exposure to combustion emissions among fire investigators who inspect fire scenes at buildings with CCA-treated lumber as part of their construction

Keywords: SIC 9224 (fire departments), arsenic, copper, chromium, chromated copper arsenic, CCA, treated lumber

Abstract: The Bureau of Alcohol, Tobacco, and Firearms (ATF) requested technical assistance in evaluating potential exposure to combustion emissions among fire investigators who inspect fire scenes at buildings with CCA-treated lumber as part of their construction. A fire department's response to a fire usually involves three phases: suppression, overhaul, and investigation. After a fire fighter suppression crew has extinguished the fire and ventilated the structure, an overhaul crew searches for hidden fire in walls or ceilings to make sure the fire has been completely extinguished. Fire scene investigators then examine the structure to determine the origin and cause of the fire. Typically, the same fire fighters who suppress the fire also perform the overhaul. Also, fire investigators are sometimes involved in the overhaul phase to help ensure the preservation of evidence.

Combustion products typically present at fire scenes include $\mathrm{CO}$, hydrogen cyanide, $\mathrm{NO}_{\mathrm{x}}$, aldehydes, and particulates. While suppression crews typically use SCBAs to protect against respiratory hazards, many departments do not require their use during overhaul. Fire investigators rarely use respirators even though a considerable amount of smoldering debris may be present. CCA-treated wood is used extensively in outdoor construction of decks, porches, railings, playgrounds, etc. In Hawaii, CCA-treated lumber is also used for interior residential and business construction because of large populations of termites in the tropical climate. Particulates containing copper, chromium, and arsenic are emitted when CCA-treated wood is burned.

Investigators from NIOSH and the Bureau of ATF conducted an evaluation of potential fire fighter exposure to CCA combustion emissions. The study was conducted during a controlled burn at a residence with simulated CCA interior construction in conjunction with a previously scheduled ATF training activity in Kinston, North Carolina. The structure was an $825 \mathrm{ft}^{2}$ single family, one-story, wood frame residence. In one 8 - $\mathrm{ft} \times 9$-ft bedroom, four walls were constructed using a total of 12 CCA-treated $2 X 4 \mathrm{~s}$, and six sheets of CCA-treated $1 / 2$-inch plywood. Labels on the wood indicated it was treated in October 1998, by New South Inc., Conway, South Carolina. A small amount of leftover CCA-treated wood was placed on a stuffed recliner along with some straw in a corner of the bedroom. Five to seven minutes after the straw was ignited, the fire spread to some foam padding under the living room carpet and caused the living room to flash over. The local Fire Department Safety Officer allowed the test bedroom to burn for two or three minutes after the living room flashed over before deciding that he needed to send in the first suppression crew to prevent losing the building. The CCA-treated wood test burn was the first of 4 test burns scheduled for the building. Further evaluation of CCA combustion emissions was attempted in Hawaii. An ATF investigator was equipped with air sampling equipment in the hopes of obtaining exposure data from actual fire scenes that may involve CCA-treated wood. However, because of a low number of residential fires during the study period and problems with the air sampling equipment, no useable air samples were collected.

PBZ total particulate concentrations ranged from 37 to $320 \mathrm{mg} / \mathrm{m}^{3}$ for the suppression and overhaul crews. These fire fighters wore SCBA respiratory protection. The investigators were exposed to 0.6 and $1.5 \mathrm{mg} / \mathrm{m}^{3}$ of total particulate during their 15-minute exposure period. The OSHA 8-hour PEL for "particulates not otherwise regulated" is $15 \mathrm{mg} / \mathrm{m}^{3}$. Trace amounts of copper were found in one sup- 
pression crew air sample, and trace amounts of chromium VI were found in the PBZ air samples of one overhaul fire fighter and one investigator. Trace levels are above the LOD but below the LOQ, therefore, they should be considered approximate values. The NIOSH 8-hour RELs for copper fume and Cr VI are $0.1 \mathrm{mg} / \mathrm{m}^{3}$ and $0.001 \mathrm{mg} / \mathrm{m}^{3}$, respectively. Soot from the charred CCA-treated wood contained 3,500 ppm of arsenic, 5,800 ppm of total chromium, $2.3 \mathrm{ppm}$ of $\mathrm{Cr} \mathrm{VI}$, and 3,900 ppm of copper. Soot from the untreated wood contained less than 9 ppm of arsenic, less than 2 ppm of total chromium, approximately $0.01 \mathrm{ppm}$ of $\mathrm{Cr}$ VI, and 4.2 ppm of copper.

The environmental sampling conducted during this investigation indicated that exposure to CCA contaminants among fire investigators did not exceed the relevant evaluation criteria. However, these results cannot be considered representative of potential exposures that may be encountered by investigators in actual fire scenes. The test fire in this study was quickly extinguished and the CCA-treated wood was not burned as extensively as what may occur in other situations. Also, the investigators' duration of exposure was shorter with less debris being moved than the work that often occurs at typical fire scenes. Considering the high levels of arsenic and chromium found in the bulk samples, and the high exposure to respirable dust found among fire investigators during a previous NIOSH study, it was possible that exposure to airborne CCA contaminants could be much higher during actual fire scenes. People have been severely poisoned after burning CCA-treated wood for indoor heating. Health problems involved the eyes, respiratory system, central nervous system, gastrointestinal tract, blood, reproductive system, skin, and hair. Exposure to arsenic pentoxide was thought to be the compound primarily responsible for most of the health problems. A previous NIOSH HHE documented the potential for fire investigators to also be exposed to aldehydes, cyanide, organic vapors, acids, and polynuclear aromatic hydrocarbons. Recommendations for respiratory protection and a respiratory protection program were provided, as well as for improving ventilation whenever possible.

\section{APPENDIX}

In the NIOSH Alert: Preventing Injuries and Deaths of Fire Fighters, NIOSH recommends that fire departments take the following precautions to protect fire fighters from injury and death:

1. Establish and implement an incident management system with written SOPs for all fire fighters. The system should include a well-coordinated approach to the emergency, accountability of all fire fighters, and provisions for their overall safety at the scene of the emergency.

2. Develop and implement a written respirator maintenance program for all respiratory protective equipment used by fire fighters. Establish service and maintenance procedures and rigidly enforce them to provide respirators that are dependable and are constantly evaluated, tested, and maintained.

3. Establish and implement a system of accountability that will enable the commander at the scene of the emergency to account for the location and function of each company or unit at the scene. Also use a standard personnel identification system that can rapidly account for each department member at the scene.

4. Employ a buddy system whenever fire fighters wear SCBAs.

5. Provide PASS devices and ensure that fire fighters wear and activate them when they are involved in fire-fighting, rescue, or other hazardous duties.

6. Encourage municipalities to review and amend their elevator and life safety codes to require fire fighter control for all elevators with a total travel distance greater than 25 feet. 
7. Guard against heat stress and other medical emergencies at the fire scene; provide cool water supplies, rest areas, and access to emergency medical personnel.

NIOSH also recommends that the fire fighters take the following precautions to protect themselves from injury and death:

1. Follow all established policies and procedures.

2. Wear and activate your PASS device at the scene of every emergency.

3. Wear the appropriate protective clothing and equipment (including your SCBA) at all incidents where hazardous atmospheres might be encountered.

4. Check your SCBA to assure that it is in working order and has been properly maintained.

5. Drink fluids frequently and be aware of signs of heat stress.

\section{REFERENCES}

1. Reichelt PA, Conrad KM (1995).

Musculoskeletal injury: ergonomics and physical fitness in fire fighters. In: Orris $\mathrm{P}$, Melius J, Duffy RM, eds. Occupational medicine: state of the art reviews: fire fighters' safety and health. Vol. 10, No. 4. Philadelphia, PA: Hanley \& Belfus, Inc., October-December, p. 735.

2. Orris P, Melius J, Duffy RM, eds. (1995). Occupational medicine: state of the art reviews: fire fighters' safety and health. Vol. 10, No. 4. Philadelphia, PA: Hanley \& Belfus, Inc., October-December.

3. Balwin TN (2001). Basement fires: A lethal trap. American Fire Journal 12-16.

4. NIOSH.(1994). NIOSH Alert: Request for Assistance in Preventing Injuries and Deaths of Fire Fighters. Cincinnati, $\mathrm{OH}$ : U.S. Department of Health and Human Services, Public Health Service, Centers for Disease Control and Prevention, National Institute for Occupational Safety and Health, DHHS (NIOSH) Publication No. 94-125.
5. ILO (1983). Todradze C, Diesel engines, underground use of. In: Encyclopedia of occupational health and safety. Vol. I/a-k. Geneva, Switzerland: International Labour Office.

6. NIOSH (1988). Current intelligence bulletin 50: carcinogenic effects of exposure to diesel exhaust. Cincinnati, OH: U.S. Department of Health and Human Services, Public Health Service, Centers for Disease Control, National Institute for Occupational Safety and Health, DHHS (NIOSH) Publication No. 88-1 16.

7. Garshick E, Schenker MB, Munoz A, Segal M, Smith TJ, Woskie SR, Hammond SK, Speizer FE (1987). A case-control study of lung cancer and diesel exhaust exposure in railroad workers. Am Rev Respir Dis 135(6): $1242-1248$.

8. ACGIH (2001). Threshold limit values and biological exposure indices for chemical substances and physical agents, diesel exhaust (measured as elemental carbon). Cincinnati, OH: American Conference of Governmental Industrial Hygienists.

9. Gamble J, Jones W, Mishall S (1987). Epidemiological-environmental study of diesel bus garage workers: acute effects of $\mathrm{NO}_{2}$ and respirable particulate on the respiratory system. Env Res 42(1):201-214.

10. Reger R, Hancock J (1980). Coal miners exposed to diesel exhaust emissions. In: Rom W, Archer V, eds. Health implications of new energy technologies. Ann Arbor, MI: Ann Arbor Science Publishers, Inc., Pp. $212-231$

11. Ulfvarson U, Alexandersson R (1990). Reduction in adverse effect on pulmonary function after exposure to filtered diesel exhaust. Am J Ind Med 17(3):341-347.

12. Birch, ME, Cary, RA (1996). Elemental carbon-based method for monitoring occupational exposures to particulate diesel exhaust. Aerosol Sci Technol 25:221-241.

13. Zaebst D, Clapp D, Blade L, Marlow D, Steenland K, Hornung R, Scheutzle D, Butler J (1991). Quantitative determination of trucking industry workers' exposure to diesel exhaust particles. Am Ind Hyg Assoc J 52(12):529-541. 